\title{
Atributos que caracterizan una megalópolis
}

\author{
Atributos que caracterizam uma megalópole
}

Attributes that characterize a megalopolis

Manuel Meireles[a], Cida Sanches ${ }^{[b]}$

${ }^{[a]}$ Universidad Nacional de Córdoba (CEA), Córdoba, Argentina
${ }^{[b]}$ Faculdade Campo Limpo Paulista (FACCAMP), Campo Limpo Paulista, SP, Brasil

\section{Resumen}

El objetivo del trabajo es definir cuáles son los atributos específicos de una megalópolis. El estudio es cualitativo y empleó grupos de discusión con 19 especialistas que trabajaron según la perspectiva metodológica interdisciplinaria que se puede ver en Delich. Los datos fueron recolectados, tabulados y analizados según el Método para Asignación de Características a Objeto (MACO) inspirado en el método de Kano adecuadamente ajustado. La técnica de ese modelo posibilita definir si una determinada característica pertenece o no a un objeto específico. En el estudio el objeto es la megalópolis. Los resultados muestran que, considerando los atributos específicos e importantes, hay fundamentalmente 20 atributos que deben ser tenidos en cuenta. Sin embargo, los atributos específicos (los más importantes) de adherencia muy fuerte, que una concentración integrada de personas, actividades y riquezas debe tener para ser reconocida como megalópolis, son cinco. Ese resultado posibilita que se pueda efectivamente reconocer si una aglomeración urbana es o no es una megalópolis.

Palabras clave: Megalópolis. Atributos. Perspectiva metodológica interdisciplinaria. Método para asignación de características a objeto.

\section{Resumo}

O objetivo do trabalho é definir quais são os atributos específicos de uma megalópole. O estudo é qualitativo e utilizou grupos de discussão com 19 especialistas que trabalharam de acordo com a perspectiva metodológica interdisciplinar, que pode ser vista em Delich. Os dados foram coletados, tabulados e analisados de acordo com o Método de Atribuição de Características para Objeto (MACO), inspirado no método de Kano, adequadamente ajustado. A técnica desse modelo permite definir se determinada característica pertence a um objeto específico ou não. No estudo, o objeto é a megalópole. Os resultados mostram que, considerando os atributos específicos e importantes, existem basicamente 20 atributos que devem ser levados em consideração. No entanto, os atributos específicos (o mais importante) de adesão muito forte, os quais uma concentração integrada de pessoas, atividades e riqueza deve ter para ser reconhecida como megacidade, são cinco. Esse resultado permite reconhecer efetivamente se uma aglomeração urbana é ou não uma megalópole.

Palavras-chave: Megalópole. Atributos. Perspectiva metodológica interdisciplinar. Método de atribuição de características para objeto.

MM és Doctorado en Ingeniería de Producción por la Universidad de São Paulo (USP-Poli), e-mail: profmeireles@uol.com.br CS és Ph.D. en Ciencias por la Universidad Federal de São Paulo (UNIFESP/EPM), e-mail: cidasanches@uol.com.br 


\section{Abstract}

This work aims to define the specific attributes of a megalopolis. The study is qualitative and used discussion groups with 19 specialists who worked according to the interdisciplinary methodological perspective proposed by Delich. Data were collected, tabulated and analyzed according to the Method for Assigning Characteristics to Object (MACO), inspired by the method of Kano. This technique allows defining whether a certain characteristic belongs to a specific object or not. In the study, the object is the megalopolis. The results show that, considering the specific and important attributes, there are basically 20 attributes that must be taken into account. However, there are five specific attributes (the most important) that need recognition in megalopolis: strong adherence, integrated concentration of people, activities and wealth. This result allows the effectively recognition of whether an urban agglomeration is or is not a megalopolis.

Keywords: Megalopolis. Attributes. Interdisciplinary methodological perspective. Method for assigning characteristics to object.

\section{Introducción}

En el verano pasado, durante una pesca yo me perdí entre los arbustos, pero finalmente encontré un rastro que me llevó a un grupo de casitas de madera y a un pequeño almacén. Charlando con la dueña del negocio, le dije: -Cómo son agradables el silencio y la paz del campo tan diferentes de la agitación loca de las ciudades; acá no hay tránsito ni multitud obligándonos a correr.-Bien -respondió ella muy educadamente- yo no sé si usted está correcto, porque yo nunca viví en el campo: siempre viví acá mismo en la ciudad (Flint, 1954, p. 70).

Ese texto muestra bien como es difícil comprender qué es una ciudad, entender cómo un objeto multiforme se hace difícil de comprender en su plenitud. Una megalópolis, una 'Gran ciudad' presenta las mismas dificultades. Megalópolis expresa una creciente forma de organismo físico y socioeconómico resultante de aglomeraciones urbanas que requieren gobierno y administración bien definidos. Pero ¿cuáles son los atributos que caracterizan una megalópolis? De esos atributos ¿cuáles son los más importantes? El objetivo de este trabajo es contestar a esas preguntas. El estudio consideró un amplio conjunto de factores (económicos, antropológicos, psicológicos, sociológicos, artísticos y políticos) que pueden ser considerados, en la literatura, como atributos fundamentales de una megalópolis.

El objetivo del trabajo es definir cuáles son los factores que caracterizan una megalópolis, o, en otras palabras y más específicamente, cuales atributos son específicos de una megalópolis. Estos atributos no se definen previamente por la revisión de la literatura o similar, pero elegidos a partir de una lista (Cuadro 1) mediante el Método para Asignación de Características a Objeto (MACO). Lo que se busca, en síntesis, es definir los elementos más importantes de una megalópolis. Y, según Sant’Anna (2005, p. 2) una definición debe, de algún modo, destacar una subclase (o especie) a través de características especiales. Y el autor sigue diciendo que

[...] hay por lo menos dos partes en una definición: hay aquello que se desea definir (definiendum) y la expresión que será de hecho empleada para definir (definiens).

Se busca, por lo tanto, una lista de descriptores capaces de definir con seguridad el concepto de megalópolis. La función de los descriptores es presentar los contenidos, los puntos críticos, las características significativas de un objeto (Deponti et al. 2002).

Según Copi (1978) un descriptor debe presentar los atributos esenciales da su especie, o sea, para describir adecuadamente un objeto son necesarios sus atributos. El término atributo tiene origen del latín attributio con el sentido de propiedad característica de alguien o de algo. El atributo es un predicado del objeto. Pereira (1999) dijo que la primera reflexión sobre atributos se debe a Aristóteles en su Categorias que empieza con el ejercicio de la distinción entre la esencia de las cosas (sustancia) y su calificación o sus predicados.

Se lo puede describir, por lo tanto, a un objeto por sus atributos. Los atributos cualitativos, aunque puedan ser difíciles de parametrizar (Pereira, 1999) pueden ser indirectamente cuantificables. 
Cuadro 1 - Lista de los potenciales atributos de una megalópolis

\begin{tabular}{|c|c|}
\hline $\begin{array}{l}\text { [1]-Gran aeropuerto internacional. Debe haber un aeropuerto totalmente equipado para vuelos internacionales con destino a las } \\
\text { principales ciudades globales. Debe haber espacio al lado del aeropuerto para el crecimiento de una "aero-ciuddad". }\end{array}$ & Conway (1999); Kunzmann (1996) \\
\hline $\begin{array}{l}\text { [2]-Regiones de producción y consumo separadas y delimitadas. La ciudad es una superficie homogéneamente llana, con una región } \\
\text { central, con sistemas de transportes cubriendo todos los puntos. En ese territorio se encuentran las dos actividades urbanas, las } \\
\text { actividades empresariales y las residenciales. }\end{array}$ & Alonso (1964) \\
\hline $\begin{array}{l}\text { [3]-Autonomía políitca. Una ciudad contiene una fortaleza, un mercado, un tribunal de justicia, y tiene un carácter colectivo y también } \\
\text { autonomía poĺitica }\end{array}$ & Weber (1999) \\
\hline $\begin{array}{l}\text { [4]-Infraestructura de comunicaciones avanzada. La ciudad debe estar conectada en red y ser capaz de acomodar a las demandas de } \\
\text { comunicación de voz, imagen y datos. }\end{array}$ & Conway (1999) \\
\hline $\begin{array}{l}\text { [5]-Bolsa de Valores con influencia mundial. Reflejando el crecimiento de la ciudad, su Bolsa de Valores debe ser considerada de } \\
\text { manera global. }\end{array}$ & Duffy (1995) \\
\hline $\begin{array}{l}\text { [6]-Centros avanzados de tecnología. Debe haber un centro de excelencia en diversos campos de la tecnología. Ese centro de } \\
\text { tecnología debe reunir cientificicos de la academia, gobierno y de organizaciones privadas. }\end{array}$ & Conway (1999) \\
\hline $\begin{array}{l}\text { [7]-Clima intermedio en casi todas las estaciones: el clima debe ser apacible con temperatura y humedad suficiente para ayudar a la } \\
\text { agricultura. }\end{array}$ & Kunzmann (1996) \\
\hline [8]-Complejo de industria rural. La zona rural ubicada en los alrededores de la ciudad debe ofrecer productos naturales y procesados. & Kunzmann (1996) \\
\hline $\begin{array}{l}\text { [9]-Complejos de ocio. Los 'leisure worlds' ofrecen condiciones de relajación y diversión. Deben tener parques de entretenimiento y } \\
\text { estructuras de recreación. }\end{array}$ & Kunzmann (1996) \\
\hline $\begin{array}{l}\text { [10]-Conexiones de y para el interior (hinterland conections). Deben existir rutas de transporte que efectivamente unan la megalópo- } \\
\text { lis y el interior. Autopistas circunferenciales ("rodoanéis") corresponden al sistema preferido }\end{array}$ & Conway (1999) \\
\hline [11]-Consumo per cápita alto. & Frost \& Spence (1993); Nivola (1999) \\
\hline [12]-Eficiente sistema de recogida de residuos urbanos. & Frost \& Spence (1993) \\
\hline [13]-Alta densidad de población. & Olalquiaga (1998) \\
\hline [14]-Extensa oferta de bienes y servicios & Olalquiaga (1998) \\
\hline [15]-Feria internacional & Frost \& Spence (1993) \\
\hline [16]-Fuerte circulación de bienes y servicios & Olalquiaga (1998) \\
\hline $\begin{array}{l}\text { [17]-Gobernabilidad de la región metropolitana: la construcción de la gobernabilidad metropolitana implica cambios de fuerte } \\
\text { contenido politico y, por eso, demanda participación intensa de los actores interesados en acompañar activamente las decisiones sobre } \\
\text { los recortes del sensible urbano, con el objetivo de interferir de forma decisiva en la distribución de los espacios para no permitir su } \\
\text { ocupación no justa y sin reglas. }\end{array}$ & Rancière (1996, p. 374). \\
\hline $\begin{array}{l}\text { [18]-Gran capacidad sostenible para satisfacer las necesidades fisicas y sociales de sus habitantes (alimentación, abrigo, seguridad, } \\
\text { salud, transporte y educación); }\end{array}$ & Nivola (1999) \\
\hline [19]-Gran amplitud continua de zona urbana (expansión urbana) & Angel et al. (2005) \\
\hline $\begin{array}{l}\text { [20]-Gran integración económica de las regiones conurbadas. El coniunto de localidades pertenecientes a una megalópolis presenta } \\
\text { fuerte integración económica, donde los flujos de personas y de mercaderías son intensos. En ese sentido, la infraestructura permite } \\
\text { que los desplazamientos sean ágiles, o sea, la región presenta transportes rápidos, tales como: trenes expresos, autopistas y puentes } \\
\text { aéreos. (Urani, 2008) }\end{array}$ & Urani (2008); Olalquiaga (1998) \\
\hline [21]-Gran movilidad de personas y bienes y servicios & Olalquiaga (1998) \\
\hline $\begin{array}{l}\text { [22]-Gran población (> } 10 \text { millones de habitantes): el criterio más importante para definir a la megalópolis como fenómeno es su } \\
\text { tamaño, medido por el número de habitantes: diez millones o mús. }\end{array}$ & Freitag (2006) \\
\hline $\begin{array}{l}\text { [23]-Grandes zonas verdes (infraestructura verde). Las ciudades deben prever una cantidad sustancial de espacio abierto permanente, } \\
\text { indluyendo elementos como parques, campos de golf, espacios para equitación y florestas. (Conway, 1999) }\end{array}$ & Conway (1999) \\
\hline $\begin{array}{l}\text { [24]-Grandes bienes culturales: existencia de instalaciones y oportunidades culturales (bibliotecas públicas, museos, teatros o salas } \\
\text { de exposiciones, canchas o gimnasios polideportivos, cines, shoppings y restaurantes), permitiéndoles a sus habitantes o visitantes el } \\
\text { acceso a muchas actividadas de ocio, garantizando una mejor calidad de vida. }\end{array}$ & Conway (1999) \\
\hline
\end{tabular}

Fuente: Datos recogidos por los autores. 
Cuadro 1 - Continuación...

\begin{tabular}{|c|c|}
\hline $\begin{array}{l}\text { [25]-Grandes medios de comunicación (periódicos, televisión): grandes medios de comunicación, culturales, de consumo y de } \\
\text { servicios. }\end{array}$ & Ferrier (2001) \\
\hline $\begin{array}{l}\text { [26]-Influencia y participación en eventos internacionales. Por ejemplo, la ciudad de Nueva York acoge a la Organización de las } \\
\text { Naciones Unidas, y en Bruselas se encuentran las sedes de la Organización del Tratado del Atlántico Norte y de la Unión Europea; }\end{array}$ & Doel \& Hubbard (2002), \\
\hline $\begin{array}{l}\text { [27]-Mecanismos políticos adecuados. Muchos de los puntos de la gestión de una megalópolis son grandes proyectos que cruzan } \\
\text { nuevas líneas jurisdiccionales. En muchos casos, se hace necesario un nuevo arreglo político para superar dificultades de crecimiento. }\end{array}$ & Conway (1999) \\
\hline [28]-Movilidad de las personas facilitada (calles, subtes, puentes, túneles, parques, carriles de bicicletas, carriles para peatones). & Ferrier (2001) \\
\hline [29]-Nombre reconocido internacionalmente: una persona diría Paris, y no Paris, Francia; & Doel \& Hubbard (2002), \\
\hline [30]-Presencia de grandes instituciones financieras & Kunzmann (1996) \\
\hline [31]-Proceso continuo de conurbación & Olalquiaga (1998) \\
\hline $\begin{array}{l}\text { [32]-Depósitos de agua: el agua juega papel central en el debate crítico de la ecología política y de la economía política de escalas, } \\
\text { que aborda el enredo del proceso de la reestructuración socioeconómica de las metrópolis con la transformación de la propia natura- } \\
\text { leza y del ambiente urbano. (Swyngedouw, 2009). Una ciudad con grandes perspectivas para el futuro puede tener su esperanza } \\
\text { debilitada por la escasez de agua. Es absolutamente esencial tener una oferta de agua más que suficiente. Conway (1999). }\end{array}$ & Swyngedouw (2009); Conway (1999) \\
\hline [33]-Sede de grandes conglomerados multinacionales & Witlox et al. (2004) \\
\hline [34]-Sede de grandes instituciones educacionales & Freitag (2006) \\
\hline [35]-Servicios públicos esenciales garantizados (agua, electricidad, internet, recolección de aguas residuales y basura) & Freitag (2006); Nivola (1999) \\
\hline $\begin{array}{l}\text { [36]-Sistema avanzado y eficiente de transportes. Debe haber un sistema de transporte rápido y eficiente para servir a todos los } \\
\text { elementos de la población. Los crecientes embotellamientos del tránsito son la ruina de toda ciudad. (Conway, 1999) }\end{array}$ & Olalquiaga (1998); Conway (1999) \\
\hline [37]-Suelo bueno en la región agrícola periférica & Kunzmann (1996) \\
\hline [38]-Calidad de vida sostenible & Freitag (2006) \\
\hline $\begin{array}{l}\text { [39]-Hay un gran número de multimillonarios y billonarios atraídos por la economía saludable y dinámica generalmente presente en } \\
\text { las megalópolis. }\end{array}$ & Nivola (1999) \\
\hline $\begin{array}{l}\text { [40]-Presenta influencia económica nacional (papel económico). Las metrópolis aumentaron su función inductora del desarrollo econó- } \\
\text { mico nacional (Ribeiro, 2008). El sistema urbano como un todo también puede influenciar a la competitividad nacional. (Markusen } \\
\text { 1996). }\end{array}$ & Ribeiro (2008); Markusen (1996), \\
\hline [41]-Hay centros (industriales, comerciales y residenciales): que atraen habitantes e inversiones privadas & Olalquiaga (1998) \\
\hline [42]-Tener buena ubicación geográfica & Kunzmann (1996) \\
\hline [43]-Topografía no accidentada & Kunzmann (1996) \\
\hline
\end{tabular}

Fuente: Datos recogidos por los autores.

Para definir la expresión megalópolis se buscarán sus principales atributos. En el próximo capítulo será exhibida una lista de atributos obtenida en la literatura. En el capítulo siguiente se describe el método para que se pueda pasar del definiendum al definiens. En el capítulo 4 son presentados los resultados y, por fin las conclusiones y recomendaciones.

\section{Megalópolis}

En 1961, un geógrafo francés publicó un estudio grandioso de la región altamente urbanizada ubicada en el noreste de los Estados Unidos. Jean Gottmann pasó 20 años investigando la región que va del sur de New Hampshire a Massachusetts, norte de Washington, DC. Él argumentó que se trataba de una "región muy especial", y le dio el nombre de Megalópolis.

Debemos abandonar la idea de que una ciudad es una unidad firmemente establecida y organizada, en la que personas, actividades y riquezas están ubicadas en una zona muy pequeña claramente separada de sus alrededores no urbanos. Cada ciudad en esa región se propaga por toda parte alrededor de su núcleo original que crece en medio a una mezcla irregular coloidal de paisajes rurales y de suburbio; derrite en amplias frentes 
con otras mezclas, con textura algo semejante a los barrios suburbanos aunque pertenecientes a otras ciudades (Gottmann, 1961, p. 5).

El proceso de megalopolización se caracteriza por las sucesivas junciones de nuevas pequeñas ciudades a otras grandes ciudades principales para crear una cadena industrial (Mori, 1997). Ese proceso generalmente empieza con el desarrollo de una metrópolis.

Etimológicamente, la palabra metrópolis remite a la Grecia Antigua, y su sentido se refería a la designación de la Ciudad Madre, a la gran ciudad que tenía funciones de las cuales dependían las demás. Entonces, la metrópolis se refería al control de un territorio, a la oferta de bienes y servicios diferenciados para una región (Di Méo, 2008).

Por metrópolis se entiende una gran ciudad "[...] con tradición histórica frecuentemente centenaria (Berlín) o milenaria (Lisboa, Roma)", con una población con alrededor de cinco millones (Freitag, 2006, p. 35). Ascher (1995, p. 33) entiende el proceso de metropolización como la creciente concentración de

[...] hombres, actividades y riquezas en las aglomeraciones de muchos cientos de miles de habitantes, multifuncionales, fuertemente integradas a la economía internacional.

En el paso siguiente la metrópolis se transforma en una Región Metropolitana o semejante, que comprende el conjunto de municipios integrados económica y socialmente a ella. Tales municipios dividen con la metrópolis una estructura ocupacional y una forma de organización del espacio característica y representan, en el desarrollo del proceso, su zona de expansión próxima o remota (Galvão, 1969).

Conurbación es el nombre que se da al proceso de fusión de regiones urbanas en consecuencia de su crecimiento geográfico (Villaça, 2012).

\section{Atributos de una megalópolis}

Para una gran ciudad la literatura señala, de manera pacífica tres características: (1) posee una población con más de 1 millón de personas; (2) presenta una capacidad sostenible para atender a las necesidades físicas y sociales de sus habitantes (alimentación, abrigo, seguridad, salud, transporte y educación); (3) y tiene un ambiente de economía saludable y dinámica que crea, atrae y estimula inversiones económicas que producen "adequate jobs", o sea, trabajo adecuado e ingresos públicos (Nivola, 1999). Ya, acerca de una megalópolis, no son todavía unánimes las características o atributos que ella debe tener. Una revisión de la literatura sobre el tema propició una lista de 43 atributos como muestra el Cuadro 1. La elección de tales atributos consideró la perspectiva metodológica interdisciplinaria de Delich (2002) con elementos pertinentes al Estado, a la Nación, a la Sociedad Civil y al Mercado, de alguna forma asociados (o potencialmente asociables) a una Megalópolis. Los atributos se presentan en orden alfabético. Basado en esos atributos se desarrolló este trabajo con el fin de obtener respuestas para las preguntas anteriores.

La investigación inicial examinó la presencia de las palabras "megalopolis", "city", "characteristics of megalopolis", "attributes of megalopolis" y otras palabras como "food", "safety", "health", "transportation" y "education" en: título, resumen o en las palabras clave de artículos científicos en las bases de datos: EBSCO, JStor, ABI y ProQuest. De esta investigación regresaron 169 artículos de los cuales se hizo una lectura del tipo skimming (Duggan \& Payne, 2009), con vistas a separar los artículos que apuntaban características de megalópolis y de ciudades de los demás. De los 60 artículos seleccionados fue hecha después una lectura más profunda buscando características de megalópolis o de grandes ciudades que pudieran de alguna forma ser sometidas al análisis de los especialistas por el método MACO, resultando en 43 atributos listados en el Cuadro1.

Para llegar al objetivo del estudio se empleó el método descripto en el próximo capítulo.

\section{Método}

El estudio es cualitativo y empleó grupos de discusión conforme Canales \& Peinado (1994) e Ibáñez (1989) según la perspectiva metodológica interdisciplinaria como se puede ver en Delich (2002, p. 81), involucrando al Estado, a la Nación, al Mercado y a la Sociedad civil que

[...] tienen una extensa tradición intelectual, acentuada en estos últimos dos siglos en occidente, que convierten esos conceptos en actos, en sujetos históricos, en objetos privilegiados de 
análisis, en orígenes causales de los fenómenos sociales más significativos de fin de siglo.

Estado, Nación, Mercado y Sociedad civil son nombradas aquí 'dimensiones autónomas' como las llama Delich (2002, p. 80). La perspectiva interdisciplinar se usa para estratificar los atributos y la análisis cualitativa fue hecha empleando una adaptación del método Kano como se puede ver en Kano et al. (1984), Berger (1993) y Roos et al. (2009). Por lo general el método de Kano se usa para clasificar atributos de la calidad; la idea fundamental del modelo es que los atributos de los bienes o del servicio pueden ser clasificados en categorías según creen satisfacción o insatisfacción con un nivel de desarrollo (Huiskonen \& Pirttilä, 1998).

El método aquí empleado para la selección de los atributos, inspirado en el método de Kano et al. (1984) y adecuadamente ajustado, se llama Método para Asignación de Características a Objeto (MACO) y, en este caso el objeto es la megalópolis.

\section{Muestra y recolección de datos}

Los grupos de discusión (GD) se constituyen de 19 profesores de programas de maestría y doctorado involucrando las áreas de Antropología (1), Derecho
(2), Economía (3), Filosofía Política (2), Geografía (1), Historia (3), Psicología (3) y Sociología (4). Los miembros de los GD son aquí llamados especialistas. El concepto de especialista es amplio e incluye desde la experiencia académica hasta las personas cuyas experiencias de vida sean significativas para la cuestión en estudio (Silva et al. 2002).

Los instrumentos de recolección fueron dos: i) las informaciones exhibidas en el Cuadro 1 empleadas en GD para asociar los atributos de una megalópolis a las dimensiones autónomas; y ii) los modelos de recolección del MACO exhibidos en el Cuadro 2. Este cuadro ejemplifica la respuesta de un especialista para los atributos de megalópolis de la dimensión autónoma Nación (13, 22, 23, 29 y 42). Proceso semejante se hizo para los atributos $(3,7,10,12,17,19,27,28,32$, 35, 36, 37 y 43) de la dimensión autónoma Estado, para los atributos $(4,21,24,25,26,31,34$ y 41) de la dimensión autónoma Sociedad civil y para los atributos $(1,2,5,6,8,9,11,14,15,16,18,20,30,33,38,39$ y 40$)$ de la dimensión autónoma Mercado.

Como se observa en el Cuadro 2 , se presentó a cada uno de los especialistas un impreso con los atributos de cada una de las cuatro dimensiones autónomas con el contenido dividido en dos partes: en la parte superior se solicitaba la opinión del especialista sobre

Cuadro 2 - Ejemplo de planilla para recolección de datos por el MACO en lo que se refiere a los atributos de megalópolis de la dimensión autónoma Nación

\begin{tabular}{|c|c|c|c|c|c|c|}
\hline \multirow{6}{*}{ 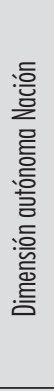 } & Indique su opinión si una Megalópolis & Inaceptable & $\begin{array}{c}\text { No es bueno } \\
\text { pero es } \\
\text { aceptable }\end{array}$ & $\begin{array}{l}\text { Indiferente: da } \\
\text { lo mismo }\end{array}$ & Es bueno & $\begin{array}{c}\text { Debe ser así } \\
\text { (es obrigatorio) }\end{array}$ \\
\hline & Tiene [13] alta densidad de población & & & $\mathbf{X}$ & & \\
\hline & Tiene [22] gran población (> 10 millones de habitantes) & & & & & $\mathbf{x}$ \\
\hline & Tiene [23] grandes zonas verdes (infraestructura verde) & & & & $\mathbf{x}$ & \\
\hline & Tiene un [29] nombre reconocido internacionalmente & & & & & $\mathbf{x}$ \\
\hline & Tiene una [42] buena ubicación geográfica & & & & $\mathbf{x}$ & \\
\hline \multirow{6}{*}{ 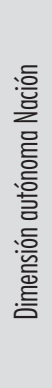 } & Indique su opinión si una Megalópolis & Inaceptable & $\begin{array}{c}\text { No es bueno } \\
\text { pero es } \\
\text { aceptable }\end{array}$ & $\begin{array}{l}\text { Indiferente: da } \\
\text { lo mismo }\end{array}$ & Es bueno & $\begin{array}{c}\text { Debe ser así } \\
\text { (es obrigatorio) }\end{array}$ \\
\hline & No tiene [13] alta densidade de población & & & & & $\mathbf{X}$ \\
\hline & No tiene [22] gran población (> 10 millones de habitantes) & $\mathbf{X}$ & & & & \\
\hline & No tiene [23] grandes zonas verdes (infraestructura verde) & & $\mathbf{X}$ & & & \\
\hline & No tiene un [29] nombre reconocido internacionalmente & $\mathbf{X}$ & & & & \\
\hline & No tiene una [42] buena ubicación geográfica & & $\mathbf{x}$ & & & \\
\hline
\end{tabular}

Fuente: Autores. 
si la megalópolis presentaba determinado atributo numerado por [n]; y en la parte inferior se solicitaba la opinión del especialista sobre si la megalópolis no presentaba dicho atributo. El especialista debería señalar una ' $X$ ' en una de las columnas que iba desde 'inaceptable' hasta 'debe ser así/es obligatorio'.

\section{Variables}

Las variables son aquí nombradas 'atributos de megalópolis' y fueron compiladas de la literatura que trata del tema. Son 43 atributos con números del [1] al [43] que fueron estratificados según su tipo, considerando las dimensiones autónomas de Delich (2002). La asociación siguió el proceso descripto abajo.

\section{Operacionalización del estudio}

El estudio presentó los siguientes pasos:

Paso i- búsqueda en la literatura de los atributos de una megalópolis (fueron señalados 43 como muestra el Cuadro 1).

Paso ii- creación de tres grupos de discusión constituidos por conveniencia: GD1 (un antropólogo, un geógrafo, un sociólogo y tres historiadores); GD2 (dos profesores de derecho, tres economistas y dos psicólogos); y GD3 (dos profesores de Filosofía Política, un psicólogo y 3 sociólogos). Esas composiciones fueron determinadas por específicas conveniencias de los especialistas.

Paso iii- primeras rondas con los GD (del 1 al 3) con el objetivo de definir para cada atributo [n] una dimensión autónoma (E, N, S, M). El objetivo era tener una lista de los atributos asociados a una única dimensión autónoma predominante: o Estado, o Nación, o Sociedad Civil, o Mercado.

Paso iv- con el objetivo de reducir desvíos y facilitar la decisión se le atribuyó a cada dimensión autónoma un rol de disciplinas (ver Cuadro 3) como se puede observar en Delich (2002).

La clasificación pasó a ser menos conflictiva, aunque algunos atributos hayan obtenido una clasificación por mayoría, como es el caso de los atributos: 'grandes medios de comunicación (periódicos, Televisión)', 'nombre reconocido internacionalmente', 'proceso continuo de conurbación', 'tener buena ubicación geográfica' y 'topografía no accidentada'. El resultado final de ese paso está en el Apéndice A y esa decisión fue considerada para los pasos siguientes.

Paso v-la clasificación de los atributos por dimensión autónoma posibilitó que se pudiera seguir empleando el MACO. La técnica de ese modelo posibilita definir si determinada característica pertenece o no a un objeto

Cuadro 3 - Cuadro de las dimensiones autónomas y respectivas disciplinas

\begin{tabular}{|c|c|c|c|c|}
\hline $\begin{array}{l}\text { Dimensiones } \\
\text { autónomas }\end{array}$ & Estado (E) & Nación (N) & Sociedad Civil (S) & Mercado (M) \\
\hline \multirow{12}{*}{ 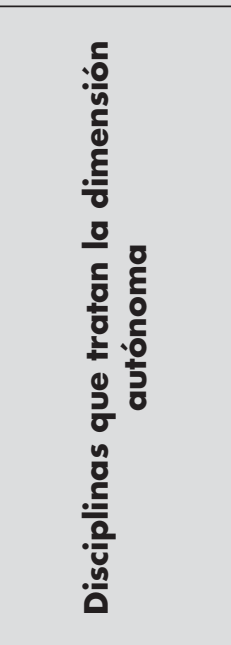 } & Ciencias Políticas & & & \\
\hline & Derecho Público & & & Derecho Comercial \\
\hline & Filosofía Política & Filosofía Política & & \\
\hline & Antropología & & Antropología & \\
\hline & Psicología & & Psicología Social & \\
\hline & & Etnología & & \\
\hline & & Historia & & Historia \\
\hline & Geografía & & & \\
\hline & & Economía & & Economía \\
\hline & & Sociología & Sociología & Sociología \\
\hline & & & Moral y ética & Moral y ética \\
\hline & Demografía & & Demografía & \\
\hline
\end{tabular}

Fuente: Delich (2002). 
específico. Para el objeto megalópolis se consideró la lista de características del Cuadro 1.

\section{Modelo para Asignación de Características a Objeto (MACO)}

El MACO parte de un rol de atributos (características) que pueden ser asociados a determinado objeto y procesa ese rol con el objetivo de estratificar tales atributos en:

- (A) atributos específicos de adherencia muy fuerte $o$ atributos que el objeto debe tener: son criterios básicos. Si esos atributos no están presentes caracterizan erróneamente el objeto;

- (B) atributos importantes de adherencia sustancial o atributos que están de acuerdo en alto grado con la esencia del objeto. Se recomienda que el objeto tenga esos atributos;

- (C) atributos medianos de adherencia moderada o atributos no relevantes para el objeto;

- (D) atributos irrelevantes de adherencia baja o atributos para los cuales es indiferente que el objeto los tenga o no; $\mathrm{y}$

- (I) atributos de adherencia insignificante $o$ atributos totalmente inapropiados para el objeto.

Para cada conjunto de atributos de determinada dimensión autónoma (ver Cuadro 2) fueron elaboradas dos preguntas. La primera se refiere a la pregunta positiva cuando determinado atributo está presente en una megalópolis; la otra pregunta del par se refiere a la parte negativa cuando ese mismo atributo no está presente en el objeto. El modelo MACO adopta el siguiente diferencial semántico:

(1) inaceptable

(2) no es bueno, pero es aceptable;

(3) indiferente: da lo mismo;

(4) es bueno; y

(5) debe ser así (es obligatorio).

Se aplicaron las encuestas, como muestra el Cuadro 2, a los especialistas de los GD y se tabularon las respuestas como muestra el Cuadro 4. Para cada miembro de los GD se tabularon las respuestas recibidas considerando cada uno de los atributos. Considérese el ejemplo del atributo '[22] gran población $>10$ millones de habitantes'. Por el Cuadro 2 se observa que el encuestado señaló en la parte de arriba el diferencial semántico ‘Debe ser así/es obligatorio’ y en la parte de abajo el diferencial semántico 'inaceptable'. Para ese encuestado es obligatorio que una megalópolis tenga más de 10 millones de habitantes y es inaceptable que eso no ocurra. Esa opinión fue adecuadamente tabulada como muestra el Cuadro 4. Y lo mismo ocurrió para todas las opiniones obtenidas de los 43 atributos.

Se cuentan las respuestas dadas a cada atributo. Como participaron 19 especialistas la suma de las respuestas para cada atributo debe ser también de 19 respuestas. El Cuadro 5 muestra el caso del atributo [22].

A continuación se hace la suma de los porcentajes de las respuestas. Se trata, en ese caso, de señalar las sumar en porcentajes (Cuadro 6).

Cuadro 4 - Ejemplo de tabulación de respuestas de una encuesta que se refiere al atributo [22] Gran población

\begin{tabular}{|c|c|c|c|c|c|c|}
\hline & & \multicolumn{5}{|c|}{ Pregunta negativa (disfuncional) } \\
\hline & $\begin{array}{c}\text { [22] Gran población } \\
\text { (>10 millones de habitantes) }\end{array}$ & Inaceptable & $\begin{array}{c}\text { No es bueno } \\
\text { pero es } \\
\text { aceptable }\end{array}$ & $\begin{array}{c}\text { Indiferente: da lo } \\
\text { mismo }\end{array}$ & Es bueno & $\begin{array}{c}\text { Debe ser así } \\
\text { (es obligatorio) }\end{array}$ \\
\hline \multirow{5}{*}{$\begin{array}{l}\text { Pregunta } \\
\text { positiva }\end{array}$} & Inaceptable & & & & & \\
\hline & No es bueno pero es aceptable & & & & & \\
\hline & Indiferente: da lo mismo & & & & & \\
\hline & Es bueno & & & & & \\
\hline & Debe ser así (es obrigatorio) & $x$ & & & & \\
\hline
\end{tabular}

Fuente: Autores. 
Cuadro 5 - Resultado de las respuestas que se refieren al atributo [22]

\begin{tabular}{|c|c|c|c|c|c|c|}
\hline & & \multirow{2}{*}{\multicolumn{5}{|c|}{ Pregunta negativa (disfuncional) }} \\
\hline & & & & & & \\
\hline & $\begin{array}{c}\text { [22] Gran población } \\
\text { (>10 millones de habitantes) }\end{array}$ & Inaceptable & $\begin{array}{c}\text { No es bueno } \\
\text { pero es } \\
\text { aceptable }\end{array}$ & $\begin{array}{l}\text { Indiferente: da lo } \\
\text { mismo }\end{array}$ & Es bueno & $\begin{array}{l}\text { Debe ser así } \\
\text { (es obligatorio) }\end{array}$ \\
\hline \multirow{5}{*}{$\begin{array}{l}\text { Pregunta } \\
\text { positiva }\end{array}$} & Inaceptable & & & & & \\
\hline & No es bueno pero es aceptable & & & & & \\
\hline & Indiferente: da lo mismo & & & & & \\
\hline & Es bueno & 3 & & & & \\
\hline & Debe ser asi (es obrigatorio) & 16 & & & & \\
\hline
\end{tabular}

Fuente: Autores.

Cuadro 6 - Valores en porcentajes dados al atributo [22] por los 19 especialistas

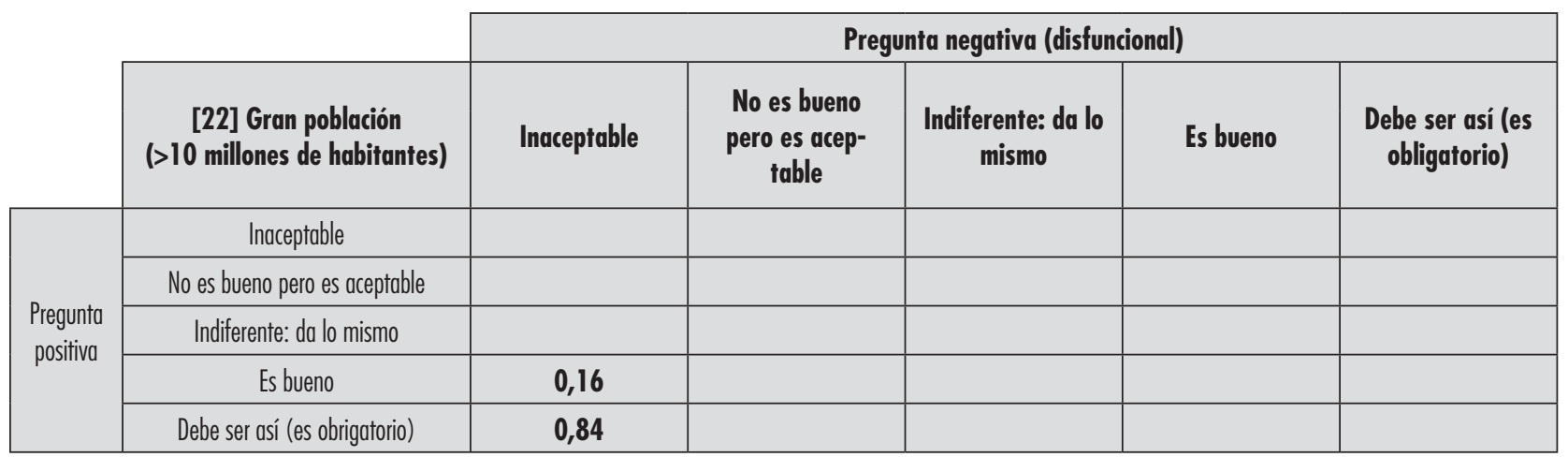

Fuente: Autores.

Cuadro 7 - Tabla de disonancia para la clasificación de los atributos según el modelo MACO: puntos y designación

\begin{tabular}{|c|c|c|c|c|c|c|c|}
\hline & & & \multicolumn{5}{|c|}{ Pregunta negativa (disfuncional) } \\
\hline & \multirow{2}{*}{\multicolumn{2}{|c|}{ Atributo }} & $\begin{array}{c}\text { Inaceptable no } \\
\text { tener }\end{array}$ & $\begin{array}{c}\text { No es bueno } \\
\text { pero es } \\
\text { aceptable no } \\
\text { tener }\end{array}$ & $\begin{array}{l}\text { Indiferente: da } \\
\text { lo mismo no } \\
\text { tener }\end{array}$ & $\begin{array}{c}\text { Es bueno no } \\
\text { tener }\end{array}$ & $\begin{array}{c}\text { Debe ser así } \\
\text { (es obligatorio } \\
\text { no tener) }\end{array}$ \\
\hline & & & 10 & 5 & 0 & -5 & -10 \\
\hline \multirow{7}{*}{$\begin{array}{l}\text { Pregunta } \\
\text { positiva }\end{array}$} & Inaceptable tener & -10 & 0 & -5 & -10 & -15 & -20 \\
\hline & No es bueno pero es aceptable tener & -5 & 5 & 0 & -5 & -10 & -15 \\
\hline & Indiferente: da lo mismo tener & 0 & 10 & 5 & 0 & -5 & -10 \\
\hline & Es bueno tener & 5 & 15 & 10 & 5 & 0 & -5 \\
\hline & Debe ser así (es obligatorio tener) & 10 & 20 & 15 & 10 & 5 & 0 \\
\hline & \multirow{2}{*}{\multicolumn{2}{|c|}{ Atributo }} & \multicolumn{5}{|c|}{ Pregunta negativa (disfuncional) } \\
\hline & & & Inaceptable & $\begin{array}{c}\text { No es bueno } \\
\text { pero es } \\
\text { aceptable }\end{array}$ & $\begin{array}{l}\text { Indiferente: da } \\
\text { lo mismo }\end{array}$ & Es bueno & $\begin{array}{c}\text { Debe ser así } \\
\text { (es obligatorio) }\end{array}$ \\
\hline \multirow{5}{*}{$\begin{array}{l}\text { Pregunta } \\
\text { positiva }\end{array}$} & \multicolumn{2}{|l|}{ Inaceptable } & ??? & I & I & I & I \\
\hline & \multicolumn{2}{|l|}{ No es bueno pero es aceptable } & D & I & I & I & I \\
\hline & \multicolumn{2}{|l|}{ Indiferente: da lo mismo } & C & D & I & I & I \\
\hline & \multicolumn{2}{|l|}{ Es bueno } & B & C & D & I & I \\
\hline & \multicolumn{2}{|l|}{ Debe ser asi (es obligatorio) } & $\mathbf{A}$ & B & C & D & ??? \\
\hline
\end{tabular}

Fuente: Autores. 
En el paso siguiente se hace la clasificación de los atributos y, para eso se lleva en cuenta el tipo mostrado en el Cuadro 7 que, en la parte de arriba muestra la importancia relativa (en puntos) de cada tipo de atributo. A esa tabla se le da el nombre de Tabla de disonancia, empleada acá esa palabra con el sentido de desarmonía, discordancia o divergencia, como son los casos señalados por las celdas de puntos nula o negativa.

Para establecer la clasificación de los atributos en A, B, C, D e I se consideró la suma de los puntos posibles como muestra la Tabla de disonancia (Cuadro 7). Los atributos de adherencia muy fuerte son los ubicados en la celda A (con el valor de 20 puntos) correspondiente a 'es obligatorio tener' e 'inaceptable no tener'. Los atributos con valor 15 están en las celdas B y se los considera atributos con adherencia sustancial. Los atributos de adherencia moderada están ubicados en las celdas C de 10 puntos; y los atributos de adherencia baja están ubicados en las celdas D, de 5 puntos. Los atributos de adherencia insignificante están ubicados en las celdas I con puntos nulos o negativos.

Cómo se observa en el Cuadro 7, el atributo '[22] gran población' obtuvo la clasificación que se ve en el Cuadro 8.

El modelo MACO emplea una matriz para especificar el tipo predominante del atributo y la posición del atributo en esa matriz se da por coordenadas que son así calculadas:

i) abscisa $x$ designada por Coeficiente de Especificidad

$\left(\mathrm{CE}_{\mathrm{x}}\right)$ que indica cuanto el atributo es propio del objeto. Se le da más importancia a los atributos ubicados en la celda A y el cálculo se hace así:
$C E_{x}=\frac{A}{T}$

sendo $\mathrm{T}=$ total .

ii) la ordenada y designada por Coeficiente de Adherencia $\left(\mathrm{CA}_{\mathrm{y}}\right)$ expresa cuanto el atributo se ajusta al objeto, cuanto el atributo es propio del objeto. Ese coeficiente considera el equilibrio entre atributos ubicados en las celdas con la B, C, D y I que se observa en el Cuadro 7 y los valores en las celdas $\mathrm{C}$ se reparten igualmente entre numerador y denominador como se observa abajo.

$C A_{y}=\frac{B}{T-A}$

sendo $\mathrm{T}=$ total.

En las dos fórmulas anteriores los valores se expresan en decimales.

Aplicando las fórmulas, en el caso del atributo '[22] gran población' (ver Cuadro 8) se tiene que:

$C E_{x}=\frac{0,84}{1}=0,84$

$C A_{y}=\frac{0,16}{1-0,84}=\frac{0,16}{0,16}=1$

Se observa el empleo de 0,0000001 para evitar la división equivocada por cero.

Los valores $\mathrm{CE}_{\mathrm{x}} \mathrm{y} \mathrm{CA}_{\mathrm{y}}$ permiten que el atributo se ubique en los cuadrantes del MACO como se ve en la Figura 1. El atributo '[22] gran población' está en el cuadrante superior derecho, hecho que lo caracteriza como atributo específico del objeto megalópolis.

Cuadro 8 - Clasificaciones del atributo '[22] gran población'

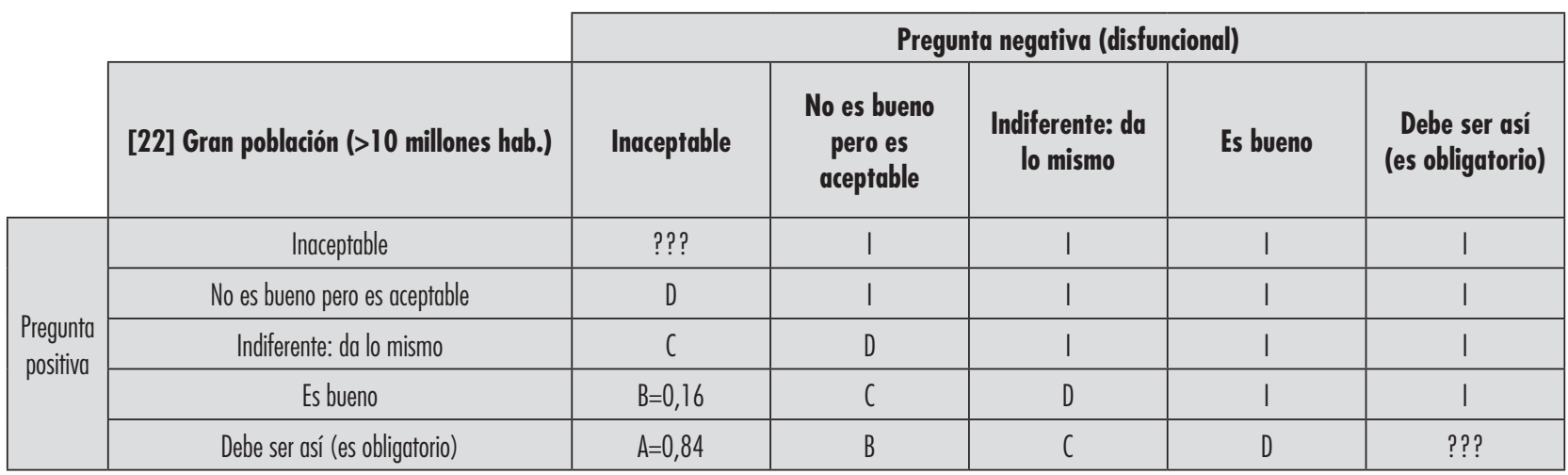

Fuente: Autores. 


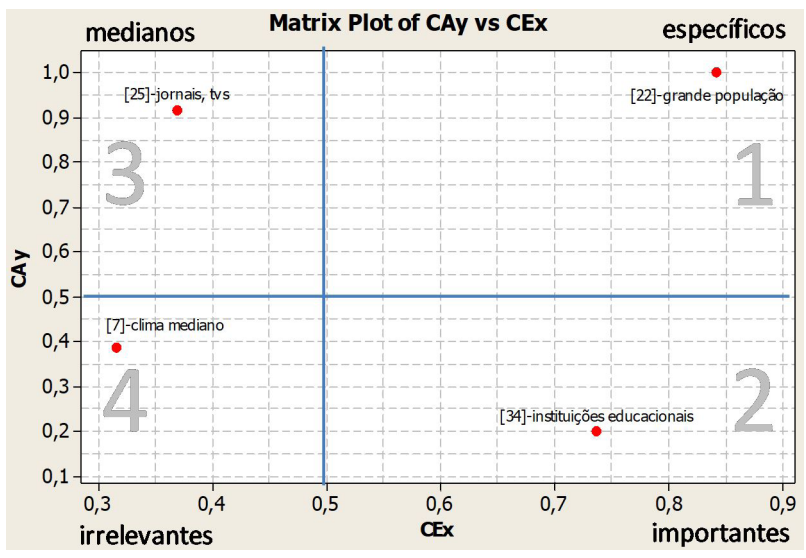

Figura 1 - Posicionamiento de los atributos en los cuadrantes del MACO Fuente: Autores.

A título de ilustración la Figura 1 exhibe otros tres atributos: el atributo '[34] sede de grandes instituciones financieras' ubicado como atributo importante; el '[25] grandes medios de comunicación (periódicos, Televisión, etc.)' ubicado como atributo mediano y el atributo '[7] clima mediano en casi todas las estaciones' ubicado como atributo irrelevante. De forma semejante se procedió para los otros atributos aquí analizados.

\section{Procesamiento de los datos}

Del procedimiento descripto en los pasos de la operacionalización del estudio y del método MACO, se obtuvo el par de coordenadas $\left(\mathrm{CE}_{\mathrm{x}} ; \mathrm{CA}_{\mathrm{y}}\right)$ respectivamente coeficiente de especificidad $\mathrm{y}$ coeficiente de adherencia para todos los atributos en análisis, como se observa en el Apéndice A. A través del Minitab r.15, función Graphs Matrix Plot se definió el cuadrante correspondiente a cada atributo.

\section{Limitaciones del método y} dificultades del estudio

El tipo de estudio aplicado en este trabajo atiende a lo que se considera estudio cualitativo "un conjunto de abordajes apropiadas para investigaciones que exigen métodos flexibles y en pequeñas unidades de muestras" (Sykes, 1990). El estudio cualitativo, de por sí, presenta algunas limitaciones: no se crean hipótesis y se desarrollan conceptos y comprensiones a contar del análisis de los datos, como dicen Adue et al.
(2008). La investigación cualitativa presenta más explícitamente la subjetividad del investigador, hecho que debilita los mecanismos de seguridad del método positivista que está presente en los procedimientos cuantitativos (Chadwick, 1984). Entonces, el tipo de estudio realizado representa un aumento de la flexibilidad en los análisis, pero también representa conclusiones no definitivas y clara subjetividad del investigador.

Además de las dificultades inherentes al método se observaron dificultades en la operacionalización, en especial en el desarrollo de la primera parte cuando los especialistas necesitaban definir para cada atributo una, y solamente una, predominante dimensión autónoma. Con excepción de la dimensión autónoma Mercado, los GD no conseguían producir una lista consensual. Los desvíos por cuenta de la función profesional eran claras: por ejemplo, los especialistas en derecho veían en muchos factores las reglamentaciones del Estado: '[1] gran aeropuerto internacional', por los especialistas en derecho, considerando la reglamentación de ellos (INFRAERO ${ }^{1}$ y ANAC $^{2}$ ) eran, obviamente de competencia del Estado. Lo mismo se puede decir de '[4] avanzada infraestructura de comunicaciones', bajo el control de ANATEL ${ }^{3}$. Se hicieron diversas rondas con los GD y, por fin, aunque sin común acuerdo, se estableció la asociación entre los 43 atributos estudiados y las cuatro dimensiones autónomas.

\footnotetext{
${ }^{1}$ INFRAERO es una empresa pública federal brasileña de administración indirecta vinculada a la Secretaría de Aviación Civil, responsable por la administración de los principales aeropuertos del país.

${ }^{2}$ Agência Nacional de Aviação Civil (ANAC) es una agencia reguladora federal cuya responsabilidad es supervisar la actividad de aviación civil en Brasil, tanto en lo que se refiere a sus aspectos económicos como a la seguridad técnica del sector. Por ejemplo, en Argentina esta función es ejercida por la Administración Nacional de Aviación Civil (ANAC) y en los Estados Unidos por la "Federal Aviation Administration".

${ }^{3}$ Agência Nacional de Telecomunicações (ANATEL) fue creada por la llamada Lei Geral de Telecomunicações (LGT) (Ley General de Telecomunicaciones), constituyendo la primera agencia reguladora a instalarse en Brasil. A través de ANATEL el Estado pasaba de la función de proveedor para la de regulador de los servicios de Telecomunicaciones. La "Federal Communications Commission" regula todos los servicios relacionados con telecomunicaciones en los Estados Unidos y, en Argentina, el marco regulatorio para el sector de las telecomunicaciones es conocido por el nombre de Argentina Digital.
} 
Se llama la atención, por lo tanto, para el hecho de que el vínculo atributo-dimensión autónoma no es un vínculo absolutamente lógico y pacífico. Aunque hayan persistido declaraciones opuestas al vínculo mostrado en el Apéndice $A$, a esta asociación se la consideró como resultado definitivo, aunque haya sido por la suma de los votos en algunos casos.

\section{Presentación y discusión de los resultados}

La ubicación de los 43 atributos de una megalópolis en los cuadrantes del MACO permite una visión gráfica de su importancia. Los resultados sintetizados en la Figura 2, señalan que en el cuadrante 1 hay cinco atributos específicos, o sea, propios de una megalópolis, y que, por sí solos la caracterizan:

[22]-Gran población (> 10 millones de habitantes);

[29]-Nombre reconocido internacionalmente;

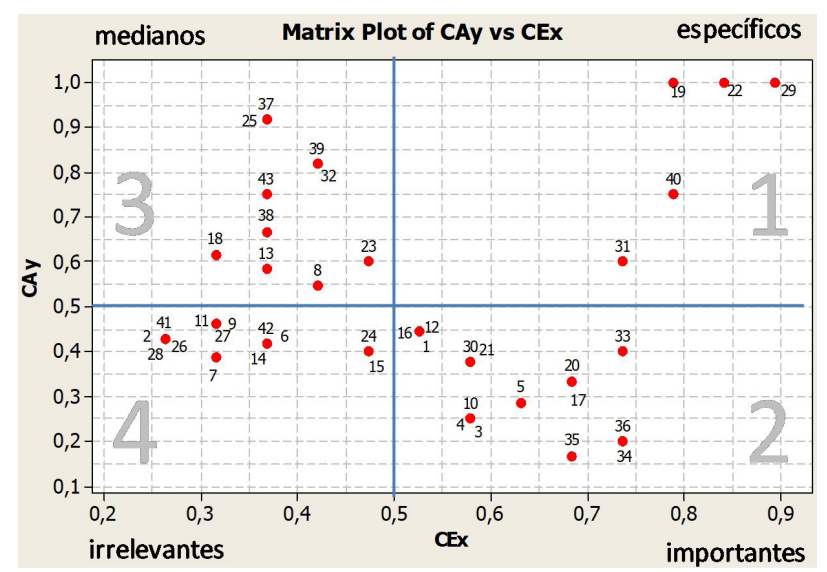

Figura 2 - Ubicación de los 43 atributos de una megalópolis en los cuadrantes del MACO

Fuente: Autores

Leyenda: [1]-aeropuerto; [2]-zonas delimitadas; [3]-autonomía política; [4]-comunicaciones; [5]-bolsa de valores; [6]-centros de tecnología; [7]-clima intermedio; [8]-complejo rural; [9]-ocio; [10]-hinterland connections; [11]-consumo alto; [12]-recogida de residuos; [13]-densidad de población; [14]-oferta de b/s; [15]-feria; [16]-circulación de b/s; [17]-gobernabilidad; [18]-alimentación, seguridad; [19]-expansión urbana; [20]-integración económica; [21]-movilidad personas/bienes; [22]-gran población; [23]-infraestructura verde; [24]-bienes culturales; [25]-periódicos, televisión; [26]-eventos internacionales; [27]-mecanismos políticos; [28]-movilidad de las personas; [29]-nombre reconocido; [30]-financieras; [31]-continua conurbación; [32]-agua; [33]-conglomerados; [34]-instituciones educacionales; [35]-servicios esenciales; [36]-transportes; [37]-suelo bueno; [38]-calidad de vida; [39]-billonarios; [40]-papel económico; [41]-centros económicos; [42]- buena ubicación; [43]-topografía llana.
[19]-Gran amplitud continua de zona urbana (expansión urbana);

[40]-Presenta influencia económica nacional (papel económico); $\mathrm{y}$

[31]-Proceso continuo de conurbación.

Se puede decir, entonces, que en la opinión de los especialistas una megalópolis presenta esos cinco atributos fundamentales.

Además de los atributos específicos los especialistas reconocieron quince atributos importantes que son los atributos facilitadores del desarrollo de una megalópolis y se encuentran en el cuadrante 2 de la Figura 2:

[20]-Gran integración económica de las regiones conurbadas;

[33]-Sede de grandes conglomerados multinacionales;

[34]-Sede de grandes instituciones educacionales;

[30]-Presencia de grandes instituciones financieras;

[5]- Bolsa de Valores con influencia mundial;

[1]- Gran Aeropuerto internacional;

[3]- Autonomía política;

[17]-Gobernabilidad de la región metropolitana;

[21]-Gran movilidad de personas y bienes y servicios;

[10]-Conexiones de y para el interior (hinterland conections);

[4]- Infraestructura de comunicaciones avanzada;

[36]-Sistema avanzado y eficiente de transportes;

[16]-Fuerte circulación de bienes y servicios;

[12]-Eficiente sistema de recogida de residuos urbanos; $y$

[35]-Servicios públicos esenciales garantizados (agua, electricidad, internet, recolección de aguas residuales y basura);

En el cuadrante 3 de la Figura 2 están ubicados los atributos medianos de adherencia moderada, atributos que no son relevantes para el objeto, o sea, que no son significativos para una megalópolis:

[18] Gran capacidad para satisfacer las necesidades sociales (alimento, seguridad, salud, transporte y educación) 
[11] Consumo per cápita alto;

[27] Mecanismos políticos adecuados;

[8] Complejo de industria rural;

[43] Topografía no accidentada;

[12] Eficiente sistema de recogida de residuos urbanos;

[13] Alta densidad de población;

[39] Presenta gran número de billonarios;

[25] Grandes medios de comunicación (periódicos, televisión);

[38] Calidad de vida sostenible;

[37] Suelo bueno en la región agrícola periférica; y

[32] Depósitos de agua.

En el cuadrante 4 de la Figura 2: están los atributos que pueden considerarse irrelevantes para el objeto, porque presentan bajo nivel de Coeficiente de Adherencia $\left(\mathrm{CA}_{\mathrm{y}}\right)$ hecho que indica que el atributo se integra poco al objeto y bajo Coeficiente de Especificidad $\left(\mathrm{CE}_{x}\right)$ que indica que el atributo no es propio del objeto:

[41] Presenta centros industriales, comerciales y residenciales;

[14] Extensa oferta de bienes y servicios;

[24] Grandes bienes culturales (museos, teatros, bibliotecas, pinacotecas);

[7] Clima intermedio en casi todas las estaciones;

[6] Centros avanzados de tecnología;

[9] Complejos de ocio;

[28] Movilidad de las personas facilitada (calles, subtes, puentes, túneles, parques, carriles de bicicletas, carriles para peatones);

[42] Tener buena ubicación geográfica;

[26] Influencia y participación en eventos internacionales;

[15] Feria internacional;

[23] Grandes zonas verdes (infraestructura verde); y

[2] Regiones de producción y consumo separadas y delimitadas.

¿Cómo se configuran los atributos de una megalópolis si los consideramos según determinada dimensión autónoma? La Figura 3 muestra la distribución de los atributos por los cuadrantes del MAPO considerando la dimensión autónoma Estado. Son 13 los atributos que se refieren a la dimensión autónoma Estado, hecho que representa el 30,23\% de los atributos analizados. Uno de los atributos específicos para la comprensión de la megalópolis pertenece a esta dimensión: el [19] Gran amplitud continua de zona urbana (expansión urbana). Ese atributo llama la atención para el territorio que, como dice Cataia (2011) es el fundamento y la fundación del Estado: "el Estado es una institución racionalizadora de dominación territorial".

Otros atributos en el ámbito del Estado, importantes para el objeto megalópolis son la [3] Autonomía política y [17] Gobernabilidad de la región metropolitana. La autonomía política no es un atributo específico: Weber (1999) ya solicitaba esa característica para las ciudades medievales. Una ciudad contendría una fortaleza, un mercado, un tribunal de justicia, y, por tener un carácter colectivo, autonomía política. En lo que se refiere al atributo gobernabilidad de la región metropolitana su importancia se da por Marques (2013, p. 4) que dice que

[...] espacios metropolitanos pueden contribuir intensamente para la reproducción de las desigualdades, tanto por la desigual distribución de servicios y oportunidades como por la presencia de altos niveles de segregación residencial. Gobiernos locales podrían cumplir un papel principal en la disminución de las situaciones desiguales, pero ellos generalmente contribuyen para reforzarlas.

Se destaca encontrar (Figura 3) el atributo '[27] Mecanismos políticos adecuados', en el cuadrante 4 , cuadrante de los atributos irrelevantes

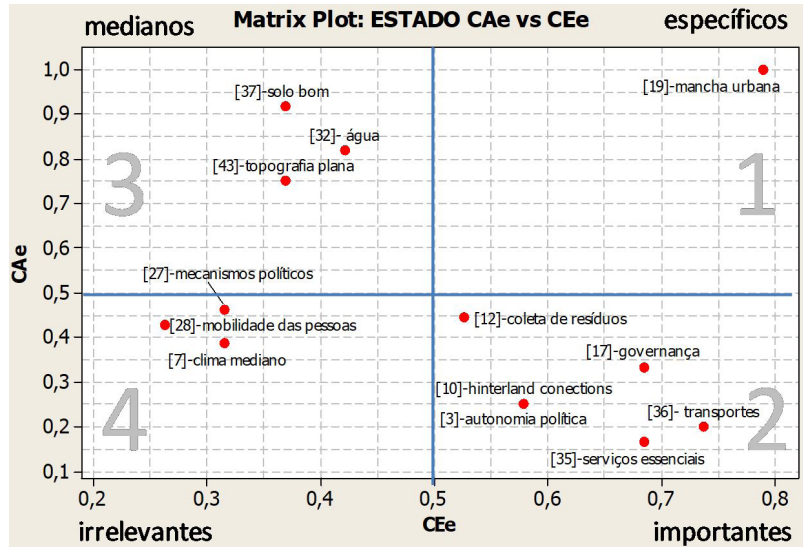

Figura 3 - Atributos relacionados a la dimensión autónoma Estado Fuente: Autores. 
para la megalópolis. Lógicamente el cuadrante más adecuado sería el cuadrante 2, estando cerca de '[17] gobernabilidad de la región metropolitana'.

En el ámbito de la dimensión autónoma Nación, de los cinco atributos considerados, solamente a uno se lo considera irrelevante: [42] Tener buena ubicación geográfica. La buena ubicación de las ciudades está en el centro de su desarrollo como se observa en Roma, Constantinopla, Lisboa. Buenos Aires no es diferente. Oliveira (2006, p. 74) llama la atención para otro ejemplo:

La ubicación considerada estratégica de Barcelona, por su apertura hacia el Mar Mediterráneo, porque es lugar de transbordo y pasaje para quien viaja hacia otros destinos turísticos en España, también facilitó la construcción de la imagen de ciudad globalizada, apta a recibir inversiones y turistas de cualquier parte del mundo, con garantía de fácil movilidad y comunicación eficiente.

El resultado del trabajo que llevó [42] la buena ubicación geográfica hacia el cuadrante de los atributos (ver Figura 4), más raro se hace cuando se observan las palabras de Jensen-Butler (1982) que dice que el espacio geográfico no puede contener ninguna función o existencia independiente. La comprensión de las estructuras espaciales lleva a comprender a las estructuras y procesos no espaciales que las crearon.

La Figura 5 muestra que de los ocho atributos del ámbito de la Sociedad Civil a tres de ellos se los consideran atributos irrelevantes para caracterizar a una megalópolis: '[24] grandes bienes culturales (museos, teatros, bibliotecas, pinacotecas)'; '[26] Influencia y

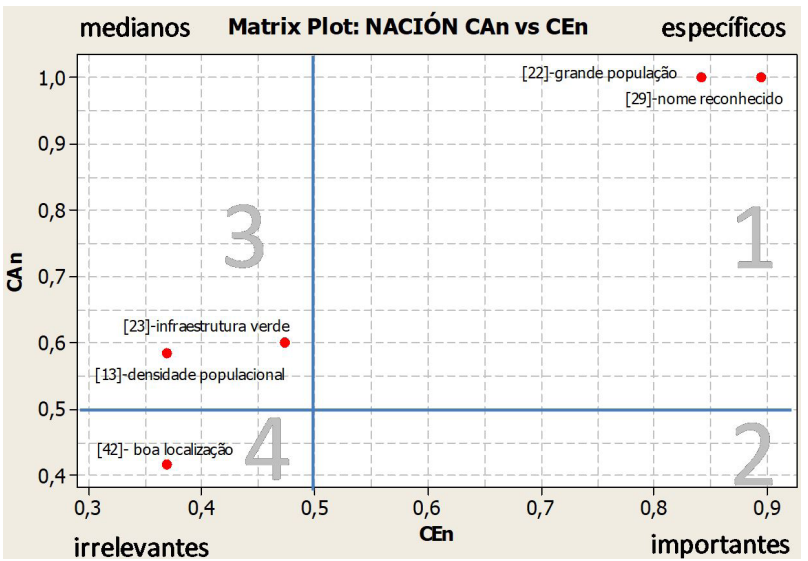

Figura 4 - Atributos que se refieren a la dimensión autónoma Nación Fuente: Autores. participación en eventos internacionales' y '[41] tener centros (industriales, comerciales y residenciales). Al atributo '[31] proceso continuo de conurbación' se lo consideró específico de una megalópolis.

La Sociedad civil debe ser comprendida acá como Delich (2002, p. 102) la defiende: "la sociedad sujeto, aquella que se define por su acción e identidad diferenciada tanto del Estado como del mercado". Ese concepto considera a la Sociedad civil como un espacio en donde se elaboran y se hacen viables proyectos globales de la sociedad, se articulan capacidades de dirección ético-políticas, se disputa el poder y la dominación (Gramsci, 2000). Lefebvre (1991) dice que el espacio contiene y está contenido en los vínculos sociales, que lo real se construye históricamente basado en representaciones de lo urbano y de la ciudad, favorecido por la actividad colectiva de los habitantes, frente a la reproducción del espacio. Y es precisamente por haber aplicado el concepto de Sociedad civil en este contexto que el hecho de tener [21] gran movilidad de personas y bienes y servicios, tener [31] proceso continuo de conurbación y tener [41] centros (industriales, comerciales y residenciales) fueron comprendidas como acciones de la Sociedad civil.

El número más grande de atributos ocurrió en el ámbito del Mercado, hecho que podría dar la percepción de que una megalópolis es esencialmente comprendida por sus características económicas. Los resultados niegan eso (ver Figura 6): de los cinco atributos específicos, los dos más relevantes se asocian al concepto de Nación ([22]-gran población con más de 10 millones de habitantes) y [29]-nombre reconocido internacionalmente (Nación)) uno al Estado ([19]-gran extensión continua de zona urbana', uno a la Sociedad civil ([31]-Proceso continuo de conurbación) y uno al

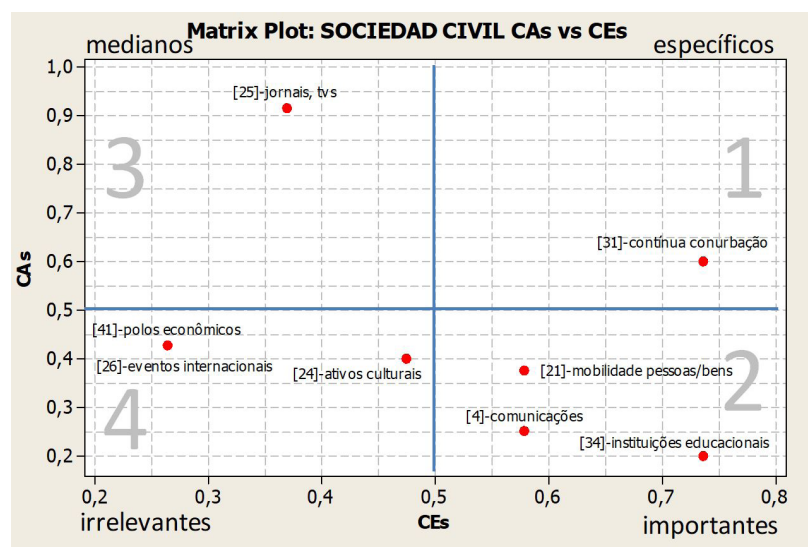

Figura 5 - Atributos que se refieren a la dimensión autónoma Sociedad civil Fuente: Autores. 
Mercado: [40]-presenta influencia económica nacional (papel económico).

\section{Conclusión y consideraciones finales}

El estudio, desde la perspectiva metodológica interdisciplinar de Delich (2002), involucrando al Estado, a la Nación, al Mercado y a la Sociedad civil, fue planeado para responder principalmente a dos preguntas: ¿cuáles son los atributos que caracterizan una megalópolis? De esos atributos ¿cuáles son los más importantes?

Considerando los atributos específicos e importantes, como se ve en la Figura 2, hay fundamentalmente

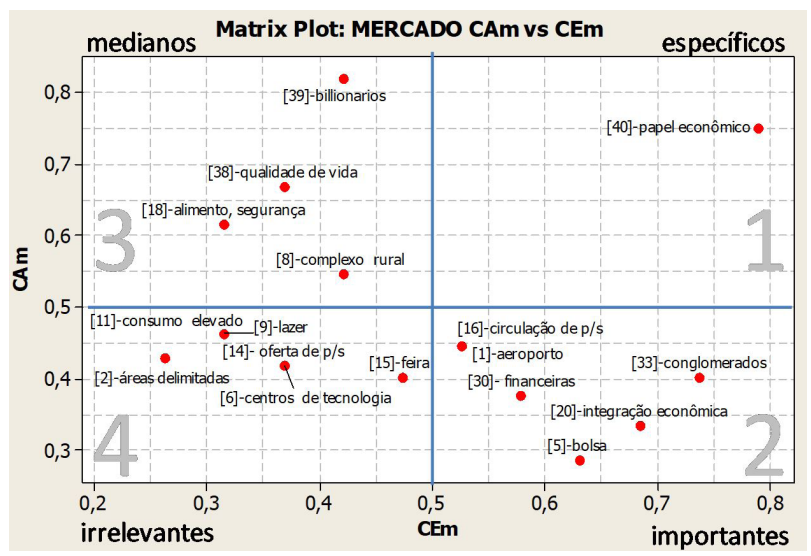

Figura 6 - Atributos relacionados a la dimensión autónoma Mercado Fuente: Autores.
20 atributos que deben ser llevados en cuenta. Sin embargo los atributos específicos (los más importantes) de adherencia muy fuerte, que una concentración integrada de personas, actividades y riquezas debe tener para ser reconocida como megalópolis son cinco: gran población (>10 millones de habitantes), nombre reconocido internacionalmente, gran amplitud continua de zona urbana (expansión urbana), influencia económica nacional y proceso continuo de conurbación.

De esa forma se puede conceptuar megalópolis como una gran población (con más de 10 millones de habitantes) ocupando una gran extensión continua de zona urbana (con miles de $\mathrm{km}^{2}$ ), con nombre reconocido internacionalmente, en continuo proceso de conurbación y con papel económico nacionalmente influyente.

Ese concepto tiene la intención de contribuir para ampliar la discusión empezada por Gottmann (1961) y muy bien llevada por Kunzmann (1996), Conway (1999), Freitag (2006), Di Méo (2008) y Marques (2013) entre otros.

La perspectiva interdisciplinar adoptada en este trabajo evidenció que la dimensión autónoma del Mercado, aunque con más número de atributos propuesto, no presenta los más importantes, teniendo en cuenta que, de los cinco atributos específicos, dos de los más relevantes se asocian a la dimensión autónoma de la Nación, uno a la dimensión Estado, otro a la Sociedad civil y, por fin uno a la dimensión autónoma Mercado.

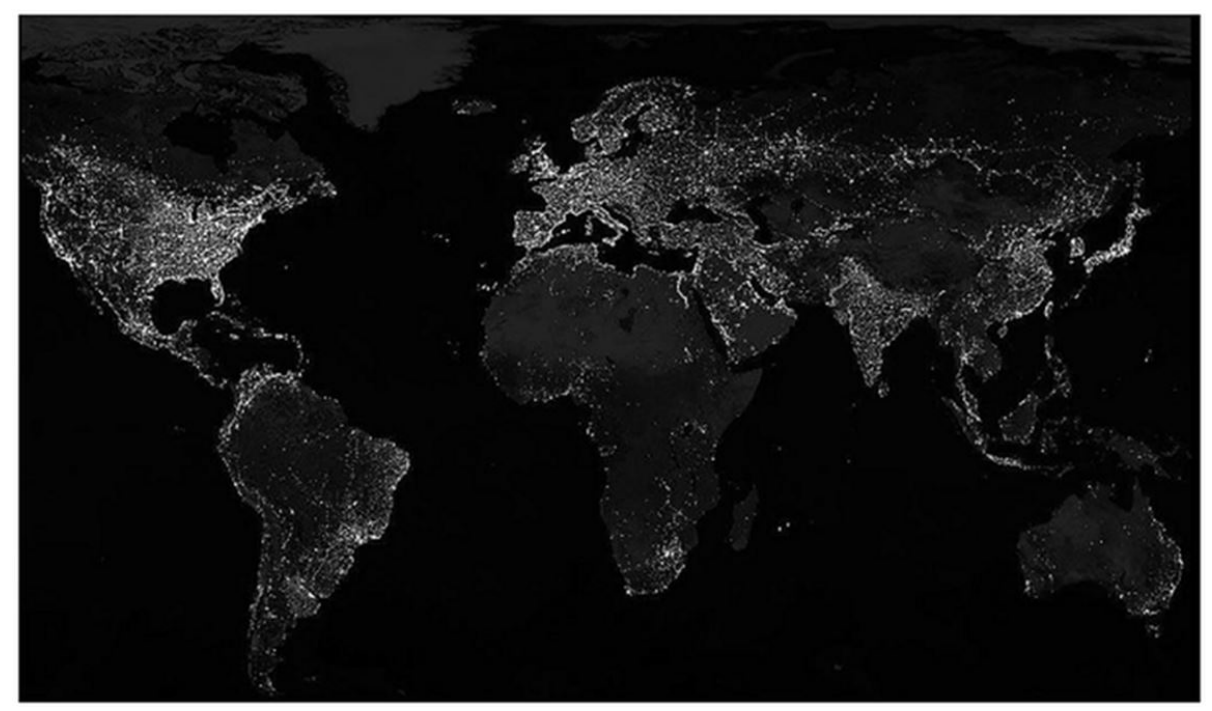

Figura 7 - Luces nocturnas vistas del Espacio

Fuente: Mayhew \& Simmon (2017) (NASA/GSFC), NOAA/ NGDC, DMSP. 
Es posible que haya faltado un atributo que hasta este momento no había sido nombrado en la literatura: se ve una megalópolis, por la noche, del espacio. Por lo menos es lo que sugiere la Figura 7, una foto del telescopio Hubble que se encuentra fuera de la atmósfera terrestre, en órbita a $593 \mathrm{~km}$ arriba del nivel del mar, con un período orbital de aproximadamente 96-97 minutos, a una velocidad de $28.000 \mathrm{Km} / \mathrm{h}$.

En lo que se refiere al Método para Asignación de Características a Objeto (MACO) inspirado en el método de Kano et al. (1984) y correctamente ajustado se puede decir que funcionó satisfactoriamente y debe ser comprobado para evaluar la pertinencia de las características de otros objetos. Como sugerencia para trabajos futuros se recomienda evaluar el empleo del MACO con grupos de discusión homogéneos, (antropólogos, geógrafos, sociólogos, historiadores, etc.), con un tipo único de especialistas para que se puedan comparar los resultados.

\section{Referencias}

Adue, I. M., Chervo, M. A., Prado, M. L., \& Carraro, T. E. (2008). Las controversias entre cuantificación y cualificaación em investigación. In M. L. Prado, M. L. Souza, \& T. E. Carraro. Investigación cualitativa em enfermería: contexto y bases conceptuales (pp. 55-67). Washington: OPAS.

Alonso, W. (1964). Location and Land Use: toward a general theory of land rent. Cambridge, Mass.: Harvard University Press. http://dx.doi.org/10.4159/harvard.9780674730854.

Angel, S., Sheppard, S. C., \& Civco, D. L. (2005). The dynamics of global urban expansion. Washington: Transport and Urban Development Department, The World Bank.

Ascher, F. (1995). Metápolis ou l'avenir des villes. Paris: Odile Jacob.

Berger, C. (1993). Kano's methods for understanding customer-defined quality. Journal of the Japanese Society for Quality Control, 2(4), 3-35.

Canales, M., \& Peinado, A. (1994). Grupos de discusión. In J. M. Delgado, \& J. Gutiérrez (Coor.), Métodos y técnicas cualitativas de investigación en ciencias sociales (pp. 288316). Madrid: Síntesis.

Cataia, A. M. (2011). Território político: fundamento e fundação do Estado. Revista Sociedade \& Natureza, 23(1), 115-125. http://dx.doi.org/10.1590/S1982-45132011000100010.
Chadwick, B. A. (1984). Social science research methods. Englewood Cliffs: Prentice Hall.

Conway, M. K. (1999). The great cities of the future. The Futurist, 33(6), 23-32.

Copi, I. M. (1978). Introdução à lógica. São Paulo: Mestre Jou.

Delich, F. (2002). La crisis en la crisis: estado, nación, sociedad y mercados en la Argentina contemporánea. Buenos Aires: Eudeba.

Deponti, C. M., Ekert, C., \& Azambuja, J. L. B. (2002). Estratégia para construção de indicadores para avaliação da sustentabilidade e monitoramento de sistemas. Agroecologia e Desenvolvimento Rural Sustentável, 3(4), 44-52.

Di Méo, G. (2008). Introdução ao debate sobre a metropolização. Confins, São Paulo, 4, 2-11.

Doel, M., \& Hubbard, P. (2002). Taking world cities literally: marketing the city in a global space of flows. City, 6(3), 351368. http://dx.doi.org/10.1080/1360481022000037779.

Duffy, H. (1995). Competitive cities: succeeding in the global economy. London: Spon. http://dx.doi. org/10.4324/9780203362310.

Duggan, G. B., \& Payne, S. J. (2009). Text skimming: the process and effectiveness of foraging through text under time pressure. Journal of Experimental Psychology. Applied, 15(3), 228-242. http://dx.doi.org/10.1037/a0016995. PMid:19751073.

Ferrier, J-P. (2001). Pour une théorie (géographique) de la métropolisation. Cahiers de la Métropolisation: enjeux et définitioin de la métropolisation, 1, 41-51.

Flint, E. (1954). Flagrantes da vida real. Seleções do Reader's Digest, 25(145), 29.

Freitag, B. (2006). Teorias da cidade. Campinas: Papirus.

Frost, M., \& Spence, N. (1993). Global city characteristics and central London employment. Urban Studies (Edinburgh, Scotland), 30(3), 547-558. http://dx.doi. org/10.1080/00420989320080541.

Galvão, M. V. (1969). Áreas de pesquisa para determinação de áreas metropolitanas. Revista Brasileira de Geografia, 31(4), 53-127.

Gottmann, J. (1961). Megalopolis: the urbanized northeastern seaboard of the United States. New York: The Twentieth Century Fund. 
Gramsci, A. (2000). Introdução ao estudo da filosofi: a filosofia de Benedetto Croce. (Vol. 1, Cadernos do cárcere) Rio de Janeiro: Civilização Brasileira.

Huiskonen, J., \& Pirttilä, T. (1998). Sharpening logistics customer service strategy planning by applying Kano's quality element classification. Production Economics, 56, 253260. http://dx.doi.org/10.1016/S0925-5273(97)00065-0.

Ibáñez, J. (1989). Cómo se realiza una investigación mediante grupos de discusión. In J. Ibáñez, \& F. Alvira, El análisis de la realidad social: métodos y técnicas de investigación (3. ed., pp. 283-297). Madrid: Alianza.

Jensen-Butler, C. (1982). Capital accumulation and regional development. Environment \& Planning A, 14(10), 13071340. http://dx.doi.org/10.1068/a141307.

Kano, N., Seraku, N., Takahashi, F., \& Tsuji, S. (1984). Attractive quality and must-be quality. Journal of the Japanese Society for Quality Control, 14(2), 39-48.

Kunzmann, K. R. (1996). Euro-megalopolis or themepark Europe? scenarios for european spatial development. International Planning Studies, 1(2), 143-163. http:// dx.doi.org/10.1080/13563479608721649.

Lefebvre, H. (1991). O direito á cidade. São Paulo: Moraes. Markusen, A. (1996). Interaction between regional and industrial policies: evidence from four countries. International Regional Science Review, 19(1-2), 49-78. http://dx.doi. org/10.1177/016001769601900205.

Marques, E. L. C. (2013). Governança em grandes metrópoles: Paris, Londres e Cidade do México e São Paulo em perspectivas comparadas. São Paulo: Centro de Estudos da Metrópole. Recuperado el 4 de enero de 2017, de http://www.fflch. usp.br/centrodametropole/1123

Mayhew, C., \& Simmon, R. (2017). Figura 12. In Centro Ciência Viva do Algarve. Núcleo de Astronomia. Astronomia On-Line. Recuperado el 11 de enero de 2017, de: http:// www.ccvalg.pt/astronomia/sistema_solar/terra.htm

Mori, T. (1997). A modeling of megalopolis formation: the maturing of city systems. Journal of Urban Economics, 42(1), 133-157.http://dx.doi.org/10.1006/juec.1996.2018.

Nivola, P. S. (1999). Are Europe's cities better? The Public Interest, 137(137), 73-84. PMid:22059276.

Olalquiaga, C. (1998). Megalópolis. São Paulo: Studio Nobel.

Oliveira, F. M. (2006). Espaço, lugar, identidade e urbanização: conceitos geográficos na abordagem do turismo (Disertación).
Departamento de Geografia, Universidade Federal de Minas Gerais, Belo Horizonte.

Pereira, J. C. R. (1999). Análise de dados qualitativos. São Paulo: Edusp.

Rancière, J. (1996). 0 dissenso. In A. Novaes (Org.), A crise da razão. São Paulo: Cia das Letras.

Ribeiro, L. C. Q. (2008). Os desafios metropolitanos e o desenvolvimento nacional. Observatório das Metrópoles, 1-9. Recuperado el 23 de enero de 2017, de: http://www. observatoriodasmetropoles.ufrj.br/lcqr_03_12_08.pdf

Roos, C.; Sartori, S.; \& Godoy, L. P. (2009). Modelo de Kano para a identificação de atributos capazes de superar as expectativas do cliente. Revista Produção Online, 9(3), 536-550.

Sant'Anna, A. S. (2005). O que é uma definição. Barueri: Manole.

Silva, A. C. N., Bernardes, R. S., Moraes, L. R. S., \& Reis, J. D. (2002). Critérios adotados para seleção de indicadores de contaminação ambiental relacionados aos resíduos sólidos de serviços de saúde: uma proposta de avaliação. Cadernos de Saude Publica, 18(5), 1401-1409. http://dx.doi. org/10.1590/S0102-311X2002000500033. PMid:12244373.

Swyngedouw, E. (2009) A cidade como um híbrido: natureza, sociedade e "urbanização-ciborgue". In H. Acselrad (Org.), A duração das cidades: sustentabilidade e risco nas políticas urbanas (pp. 99-120). Rio de Janeiro: Lamparino.

Sykes, W. (1990). Validity and reability in qualitative market research: a review of the literature. Joumal of the Market Society, 32(3), 289-328.

Urani, A. (2008). Trilhas para o Rio. São Paulo: Campus.

Villaça, F. (2012). Reflexões sobre as cidades brasileiras. São Paulo: Studio Nobel.

Weber, M. (1999). Die Stadt (Complete edition, Vol. 1). Frankfurt am Main, Tübingen: Mohr Siebeck Verlag.

Witlox, F., Vereecken, L., \& Derudder, B. (2004). Mapping the global network economy on the basis of air passenger transport flows. GaWC Research Bulletin 157. Recuperado de http://www.lboro.ac.uk/gawc/rb/rb157.html

Recibido: Mayo 26, 2017

Aprobado: Ene. 30, 2018 
Apéndice A - Tipo de dimensión autónoma y coeficiente de especificidad y coeficiente de adherencia para todos los atributos en análisis

\begin{tabular}{|c|c|c|c|c|}
\hline $\begin{array}{l}\text { Atributo } \\
\text { [n] }\end{array}$ & $\begin{array}{c}\text { Tipo de } \\
\text { dimensión } \\
\text { autónoma }\end{array}$ & Atributos & $\begin{array}{l}\text { CEx -coeficiente } \\
\text { de especificidad }\end{array}$ & $\begin{array}{l}\text { CAy -coeficiente } \\
\text { de adherencia }\end{array}$ \\
\hline 1 & M & Gran aeropuerto internacional & 0.52 & 0.43 \\
\hline 2 & M & Regiones de producción y consumo separadas y delimitadas & 0.28 & 0.44 \\
\hline 3 & $\mathrm{E}$ & Autonomía política & 0.52 & 0.27 \\
\hline 4 & $S$ & Infraestructura de comunicaciones avanzada & 0.54 & 0.22 \\
\hline 5 & M & Bolsa de Valores con influencia mundial & 0.64 & 0.29 \\
\hline 6 & M & Centros avanzados de tecnología & 0.36 & 0.47 \\
\hline 7 & $\mathrm{E}$ & Clima intermedio en casi todas las estaciones & 0.32 & 0.47 \\
\hline 8 & M & Complejo de industria rural & 0.44 & 0.83 \\
\hline 9 & M & Complejos de ocio & 0.33 & 0.47 \\
\hline 10 & $\mathrm{E}$ & Conexiones de y para el interior (hinterland conections) & 0.59 & 0.29 \\
\hline 11 & M & Consumo per cápita alto & 0.32 & 0.45 \\
\hline 12 & $\mathrm{E}$ & Eficiente sistema de recogida de residuos urbanos & 0.55 & 0.44 \\
\hline 13 & N & Alta densidad de población & 0.39 & 0.83 \\
\hline 14 & M & Extensa oferta de bienes y servicios & 0.39 & 0.47 \\
\hline 15 & M & Feria internacional & 0.45 & 0.47 \\
\hline 16 & M & Fuerte circulación de bienes y servicios & 0.53 & 0.45 \\
\hline 17 & $\mathrm{E}$ & Gobernabilidad de la región metropolitana & 0.67 & 0.38 \\
\hline 18 & M & $\begin{array}{l}\text { Gran capacidad sustentable para satisfacer las necesiddades sociales (alimentación, abrigo, seguridad, } \\
\text { salud, transporte y educación) }\end{array}$ & 0.34 & 0.77 \\
\hline 19 & $\mathrm{E}$ & Gran amplitud continua de zona urbana (expansión urbana) & 0.81 & 1.00 \\
\hline 20 & M & Gran integración económica de las regiones conurbadas & 0.69 & 0.29 \\
\hline 21 & $S$ & Gran movilidad de personas y bienes y servicios & 0.60 & 0.44 \\
\hline 22 & N & Gran población (> 10 millones de habitantes) & 0.93 & 1.00 \\
\hline 23 & N & Grandes zonas verdes (infraestructura verde). & 0.46 & 0.61 \\
\hline 24 & $S$ & Grandes bienes culturales (museos, teatros, bibliotecas, pinacotecas) & 0.46 & 0.46 \\
\hline 25 & $S$ & Grandes medios de comunicación (periódicos, televisión) & 0.34 & 0.91 \\
\hline 26 & $S$ & Influencia y participación en eventos internacionales & 0.28 & 0.44 \\
\hline 27 & $\mathrm{E}$ & Mecanismos políticos adecuados & 0.33 & 0.47 \\
\hline 28 & $\mathrm{E}$ & $\begin{array}{l}\text { Movilidad de las personas facilitada (calles, subtes, puentes, túneles, parques, carriles de bicicletas, } \\
\text { carriles para peatones) }\end{array}$ & 0.27 & 0.41 \\
\hline 29 & N & Nombre reconocido internacionalmente & 0.91 & 1.00 \\
\hline 30 & M & Presencia de grandes instituciones financieras & 0.57 & 0.33 \\
\hline 31 & $S$ & Proceso continuo de conurbación & 0.74 & 0.61 \\
\hline 32 & $\mathrm{E}$ & Depósitos de agua & 0.44 & 0.83 \\
\hline 33 & M & Sede de grandes conglomerados multinacionales & 0.72 & 0.36 \\
\hline 34 & $S$ & Sede de grandes instituciones educacionales & 0.72 & 0.17 \\
\hline 35 & $\mathrm{E}$ & $\begin{array}{l}\text { Servicios públicos esenciales garantizados (agua, electricidad, internet, recolección de aguas } \\
\text { residuales y basura) }\end{array}$ & 0.69 & 0.21 \\
\hline 36 & E & Sistema avanzado y eficiente de transportes & 0.76 & 0.10 \\
\hline 37 & $E$ & Suelo bueno en la región agrícola periférica & 0.37 & 0.88 \\
\hline
\end{tabular}


Apéndice A - Continuación...

\begin{tabular}{cclcc}
\hline $\begin{array}{c}\text { Atributo } \\
\text { [n] }\end{array}$ & $\begin{array}{c}\text { Tipo de } \\
\text { dimensión } \\
\text { autónoma }\end{array}$ & Atributos & $\begin{array}{c}\text { CEx -coeficiente } \\
\text { de especificidad }\end{array}$ & $\begin{array}{c}\text { CAy -coeficiente } \\
\text { de adherencia }\end{array}$ \\
\hline 38 & M & Calidad de vida sostenible & 0.35 & 0.64 \\
39 & M & Presenta gran número de millonarios & 0.44 & 0.83 \\
40 & M & Presenta influencia económica nacional (papel económico) & 0.87 & 0.80 \\
41 & S & Tiene centros (industriales, comerciales y residenciales) & 0.28 & 0.44 \\
42 & N & Tiene buena ubicación geográfica & 0.36 & 0.47 \\
43 & E & Topografía no accidentada & 0.37 & 0.72 \\
\hline
\end{tabular}

